\title{
Addressing Adult Medicine Inpatients at the Community Level
}

\author{
Ronald J. Lagoe, Shelly Littau \\ Hospital Executive Council, New York, USA \\ Email: hospexcl@cnymail.com
}

Received 13 April 2015; accepted 19 May 2015; published 22 May 2015

Copyright (C) 2015 by authors and Scientific Research Publishing Inc.

This work is licensed under the Creative Commons Attribution International License (CC BY). http://creativecommons.org/licenses/by/4.0/

(c) (i) Open Access

\begin{abstract}
This study evaluated the impact of adult medicine patients on hospital utilization in Syracuse, New York, a small metropolitan area including three urban hospitals. The study data indicated that the principal source of adult medicine patients, in hospital emergency departments, increased by 19 percent between 2010 and 2014. Another analysis showed that adult medicine discharges comprised the largest inpatient population and were closely correlated with changes in total discharges. The data also suggested that adult medicine patients were associated with excess inpatient stays when compared with national averages between 2010 and 2014 and that these excess days were difficult to eliminate. The study data also suggested that adult medicine patients were a major source of medical and surgical readmissions. The study identified the importance of adult medicine patients and suggested the need for further evaluation of this population.
\end{abstract}

\section{Keywords}

Hospital Utilization, Hospital Outcomes, Medicine, Surgery

\section{Introduction}

In the United States and other western nations, health care providers continue to be challenged by the need to improve efficiency [1] [2]. This need is being stimulated by high health care expenses for major payers, continued interest in service volumes by providers, and greater recognition of the linkages between increased efficiency and outcomes. Much of this need relates to the care of adult medicine patients at the community and provider specific levels.

The need for cost constraints among major health payers is well documented. In the United States, the Medicare program has resorted to administrative "productivity adjustments", including penalties for provider inefficiencies and adverse outcomes [3]-[7]. At the same time, rising Medicaid expenses continue to exert major 
pressure on state and federal budgets [8]. Health insurance costs are also challenging the viability of many private businesses.

Within health care user populations, adult medicine patients are major drivers of costs. They frequently require emergency and non elective services that consume relatively large amounts of provider resources. These costs frequently result from high levels of severity of illness that are not easily managed by providers. The resources required to care for these patients are also challenging the financial viability of Accountable Care Organizations and other cost containment mechanisms [9]-[11].

Against this background, the reimbursement of health care expenses in most nations continues to be based on service volumes. In the United States, inpatient adult medicine patients generate the largest inpatient discharge volume, although some hospitals are attempting to cover financial needs by increasing the use of inpatient and outpatient surgery. It appears that, in some communities, providers may be relying on increased service volumes to pay for increases in routine expenses such as staff salaries, pharmaceutical costs, and capital expenses.

Another important aspect of hospital efficiency involves outcomes of care. In recent years, increased interest has focused on the connection between expenses and outcomes. Studies have demonstrated that adverse outcomes such as inpatient hospital complications and readmissions are responsible for substantial health care expenditures, especially among adult medicine patients whose care is not easily planned [12] [13]. This research has been associated with the development of provider initiatives and resources to improve health care outcomes for these patients [14] [15].

This study reviewed the experience with health care efficiency, volume, and outcomes of adult medicine hospital inpatients in a small metropolitan area within the United States from the perspective of providers. It described the implications of this utilization for health care economics and for provider efforts to address them at the community level.

\section{Population and Method}

This study evaluated developments in the utilization of hospital services related to adult medicine in the metropolitan area of Syracuse, New York during a multi year period. This area includes three acute care facilities, Crouse Hospital (19,919 inpatient discharges-2014), St. Joseph's Hospital (25,531 inpatient discharges), and Upstate University Hospital (26,649 inpatient discharges). Historically, the hospitals have worked to address community needs such as those of adult medicine patients through the Hospital Executive Council.

These hospitals serve a primary and secondary acute care service area of approximately 600,000. They also provide tertiary services to the eleven county Central New York Health Service Area with a population of approximately $1,400,000$.

The study identified levels of utilization for different indicators associated with the adult medicine patients in the Syracuse hospitals and their service area as indications of the impacts of this population on the community health care system. These included emergency department utilization, inpatient discharges, inpatient lengths of stay, and inpatient readmissions.

Emergency department utilization is important for the adult medicine population in Syracuse and elsewhere because most adult medicine admissions originate as visits for this service. During 2013 and 2014, 77 - 81 percent of adult medicine inpatients in the Syracuse hospitals were admitted through the hospital emergency departments.

This study identified annual numbers of visits and ambulances received for the hospitals between 2010 and 2014. This information was collected by the Hospital Executive Council and provided to the acute care facilities in daily electronic reports.

Adult medicine inpatients constitute the largest component of total inpatient utilization in most hospitals. In the United States, this is the largest inpatient service in most acute hospitals.

This study identified numbers of inpatient discharges for adult medicine, adult surgery, obstetrics, mental health, and total discharges in the Syracuse hospitals by quarter between 2012 and 2014. The data for this analysis were obtained from patient specific information collected from the Syracuse hospitals by the Hospital Executive Council. Service definitions for the data were based on All Patient Refined Diagnosis Related Groups (APR DRGs). Changes in quarterly inpatient volumes among services were compared using Pearson Correlation Coefficients.

The study also included information concerning inpatient lengths of stay for adult medicine and other hospital 
services. Because they involve unplanned admissions, rather than scheduled procedures such as surgery, the reduction of inpatient lengths of stay for these patients constitutes a relatively greater challenge for hospital clinical managers. This information was collected from the acute care facilities by the Hospital Executive Council as part of the programs that it coordinates.

The study identified inpatient lengths of stay for adult medicine and adult surgery inpatients in the Syracuse hospitals during 2010, 2012, and 2014. These stays were compared with national lengths of stay for patients with the same All Patients Refined severity of illness. Differences between utilization in the Syracuse and national inpatient populations were identified at the unit level, for mean lengths of stay, and at the aggregate level, for the inpatient days.

The fourth component of the study evaluated inpatient readmissions within 30 days for adult medicine and adult surgery in the Syracuse hospitals. As an indicator of health care outcomes, reduction of hospital readmissions is generating increased attention in the transition from reimbursement by volume to value.

The analysis included numbers of readmissions and readmission rates for adult medicine and adult surgery in the Syracuse hospitals between January and December 2013 and 2014. The analysis was based on two definitions of inpatient readmissions within 30 days using the Potentially Preventable Readmissions software developed by $3 \mathrm{M}$ Health Information Systems. These included a definition based on numbers of readmissions and a definition based on numbers of patients with at least one readmission.

\section{Results}

The initial component of the analysis focused on emergency department utilization in the Syracuse hospitals, the source of most adult medicine inpatients, between 2010 and 2014. These data help explain recent developments in the adult medicine population. This information is summarized in Table 1.

This information demonstrated that annual emergency department visits for the combined Syracuse hospitals increased by 19.3 percent during the five year period, from 175,365 to 209,139 . The average annual rate of increase was 4.5 percent. The data also show that annual ambulance transports received by the combined hospitals increased by 24.4 percent, from 53,111 to 66,081 during the period. The average annual rate of increase was 5.7 percent.

The second component of the analysis identified quarterly numbers of inpatients by service discharged from the Syracuse hospitals between January 2012 and December 2014. This information is summarized in Table 2.

These data identified changes in quarterly discharges for total hospital discharges and major inpatient services for the combined Syracuse hospitals during the three year period. The data demonstrated that adult medicine patients comprised the largest proportions of total discharges (45 - 46 percent), compared with adult surgery (24 27 percent), obstetrics (10 percent), and inpatient mental health (6 - 7 percent).

Within these discharge volumes were several quarter to quarter increases and decreases for each service. Pearson Correlation Coefficients between the quarterly discharges for each service and total discharges demonstrated that only the changes in adult medicine utilization were closely associated with the changes in total discharges, as demonstrated by the 0.9445 correlation between the data for these populations.

This high correlation was important because the implementation of changes in Medicare criteria for medical observation, beginning in October 2013, caused discharge volumes for adult medicine patients to decline, compared with the previous year, as some former inpatients were moved to observation status. The data demonstrate that this decline affected both total discharges and adult medicine discharges to a similar degree. These changes

Table 1. Emergency department visits and ambulances received (Syracuse hospitals 2010-March 2015).

\begin{tabular}{|c|c|c|c|c|c|}
\hline & 2010 & 2011 & 2012 & 2013 & 2014 \\
\hline Total ED Visits & 175,365 & 184,570 & 199,344 & 201,968 & 209,139 \\
\hline Percent Change from Previous Year & & 5.25 & 8.00 & 1.32 & 3.55 \\
\hline Total Ambulances Received & 53,111 & 57,012 & 61,583 & 62,516 & 66,081 \\
\hline Percent Change from Previous Year & & 7.34 & 8.02 & 1.52 & 5.70 \\
\hline
\end{tabular}

Source: Hospital Executive Council. 
Table 2. Hospital inpatient discharges, by discharge quarter selected services (Syracuse hospitals 2011-2014).

\begin{tabular}{|c|c|c|c|c|c|}
\hline & Total Hospital & Adult & Adult & Obstetric & Mental \\
\hline & Discharges & Medicine & Surgery & Discharges & Health \\
\hline & Excluding & Discharges & Discharges & & Discharges \\
\hline & Well & & & & \\
\hline & Newborns & & & & \\
\hline 1Q 2011 & 17,670 & 8174 & 4216 & 1831 & 1149 \\
\hline 2Q 2011 & 17,941 & 8020 & 4326 & 2061 & 1291 \\
\hline 3Q 2011 & 18,397 & 8371 & 4433 & 2115 & 1247 \\
\hline 4Q 2011 & 17,623 & 7895 & 4330 & 1929 & 1223 \\
\hline 1Q 2012 & 18,296 & 8294 & 4487 & 1904 & 1293 \\
\hline 2Q 2012 & 18,521 & 8479 & 4510 & 1999 & 1322 \\
\hline 3Q 2012 & 18,620 & 8441 & 4515 & 2129 & 1281 \\
\hline 4Q 2012 & 19,122 & 9010 & 4761 & 1904 & 1237 \\
\hline 1Q 2013 & 18,164 & 8289 & 4631 & 1847 & 1124 \\
\hline 2Q 2013 & 18,811 & 8579 & 4700 & 1954 & 1311 \\
\hline 3Q 2013 & 18,186 & 8411 & 4466 & 2026 & 1184 \\
\hline 4Q 2013 & 17,633 & 7929 & 4756 & 1865 & 1148 \\
\hline 1Q 2014 & 17,279 & 7765 & 4562 & 1783 & 1206 \\
\hline 2Q 2014 & 18,182 & 8339 & 4848 & 1929 & 1080 \\
\hline 3Q 2014 & 18,393 & 8272 & 4840 & 2142 & 1100 \\
\hline 4Q 2014 & 18,245 & 8323 & 4913 & 1850 & 1135 \\
\hline \multicolumn{2}{|c|}{ Pearson Correlation } & 0.9445 & 0.3579 & 0.4480 & 0.3368 \\
\hline
\end{tabular}

Source: Hospital Executive Council.

were not reflected in correlations of volumes for other hospital services.

The third component of the study focused on hospital inpatient lengths of stay for adult medicine and adult surgery in the Syracuse hospitals between 2010 and 2014. Relevant data are summarized in Table 3.

Table 3. Inpatient mean lengths of stay (Syracuse hospitals adult medicine and adult surgery 2010, 2012, and 2014).

\begin{tabular}{|c|c|c|c|}
\hline & 2010 & 2012 & 2014 \\
\hline \multicolumn{4}{|l|}{ Adult Medicine } \\
\hline Number of Discharges & 32,247 & 35,270 & 33,412 \\
\hline Mean Length of Stay & 5.18 & 5.14 & 5.47 \\
\hline Severity Adjusted National Average & 4.84 & 5.00 & 5.20 \\
\hline Length of Stay Difference & 0.34 & 0.14 & 0.27 \\
\hline Patient Days Difference & 10963.98 & 4937.80 & 9021.24 \\
\hline \multicolumn{4}{|l|}{ Adult Surgery } \\
\hline Number of Discharges & 19,166 & 20,433 & 20,556 \\
\hline Mean Length of Stay & 6.25 & 6.04 & 6.05 \\
\hline Severity Adjusted National Average & 5.89 & 5.75 & 5.95 \\
\hline Length of Stay Difference & 0.36 & 0.29 & 0.10 \\
\hline Patient Days Difference & 6899.76 & 5925.57 & 2055.60 \\
\hline
\end{tabular}

Sources: Hospital Executive Council; 3M Health Information Systems. 
This information demonstrated that the inpatient adult medicine lengths of stay in the hospitals increased during this time period. The increase was most apparent between 2012 and 2014, when larger numbers of patients with lower severity of illness were shifted to medical observation. This shift was also reflected in an increase in the severity adjusted national average stay.

The data demonstrated that the national average stay for adult medicine increased at a higher rate than the stay for the Syracuse hospitals, which caused the length of stay difference to decline slightly, from 0.34 to 0.27 days between 2010 and 2014. The data also indicated that the patient days difference between the hospital and severity adjusted national stays declined slightly during the period, from 10,963 to 9021 patient days. This amounted to an excess average daily census of $30-25$ patients.

By contrast, the data in Table 3 demonstrated that the mean length of stay for adult surgery patients declined from 6.25 days to 6.05 days between 2010 and 2014. This reduction occurred as the severity of illness of the adult surgery population increased by 1.0 percent, as indicated by the severity adjusted national average. These developments caused the difference between the mean stay for adult surgery in Syracuse and the severity adjusted national average to decline by 72 percent and the number of excess days for this service to decline by 70 percent.

The fourth component of the analysis focused on hospital inpatient readmissions. Data for the Syracuse hospitals for the two definitions employed in this process for 2013 and 2014 are summarized in Table 4.

Table 4. Potentially preventable readmissions adult medicine and adult surgery (Syracuse hospitals 2013-2014).

\begin{tabular}{|c|c|c|c|c|c|c|}
\hline & \multicolumn{3}{|c|}{2013} & \multicolumn{3}{|c|}{2014} \\
\hline & $\begin{array}{c}\text { Number of } \\
\text { Readmissions }\end{array}$ & $\begin{array}{c}\text { Total } \\
\text { Discharges }\end{array}$ & Readmission Rate & $\begin{array}{c}\text { Number of } \\
\text { Readmissions }\end{array}$ & $\begin{array}{c}\text { Total } \\
\text { Discharges }\end{array}$ & Readmission Rate \\
\hline \multicolumn{7}{|l|}{ Based on Readmissions } \\
\hline Adult Medicine & 3841 & 35,869 & 10.71 & 3759 & 34,737 & 10.82 \\
\hline Adult Surgery & 287 & 18,544 & 1.55 & 345 & 19,136 & 1.80 \\
\hline \multicolumn{7}{|c|}{ Based on Initial Admissions } \\
\hline Adult Medicine & 2083 & 35,869 & 5.81 & 2208 & 34,737 & 6.36 \\
\hline Adult Surgery & 1010 & 18,544 & 5.45 & 1073 & 19,136 & 5.61 \\
\hline
\end{tabular}

Based on 3M Health Information Systems Potentially Preventable Readmissions algorithm, applied to adult medicine and adult surgery definitions by APR DRG for readmissions within 30 days. Source: Hospital Executive Council.

This information demonstrated that adult medicine patients were a major source of readmissions within 30 days of the initial admission in the hospitals according to the Potentially Preventable Readmissions algorithm. When these outcomes were defined as individual readmissions, regardless of the initial admission that preceded them, adult medicine rehospitalizations accounted for 91 - 93 percent of the total for adult medicine and adult surgery combined during the period. When these outcomes were defined as patients (initial admissions) with at least one readmission within 30 days of the initial admission, adult medicine rehospitalizations accounted for 67 percent of the total for adult medicine and adult surgery combined. The rates identified in the table demonstrated that adult medicine accounted for between 1 in 9 and 1 in 16 adult medicine patients, depending on the definition.

\section{Discussion}

This study reviewed the impact of adult medicine patients on hospital utilization in a small metropolitan area. Because health care is a local function, this approach provided information concerning actual functioning of carefor this service [16].

The first two analyses in the study demonstrated the importance of the adult medicine population with respect to hospital care volumes. The first analysis indicated that the principal source of these patients, hospital emergency department utilization, has grown at a rate of 19 to 24 percent during the past five years. The second analysis showed that adult medicine patients comprised the single largest inpatient population and was closely 
associated with changes in total hospital discharges.

The second two analyses identified some of the challenges associated with management of adult medicine utilization and outcomes. The first suggested that adult medicine patients can be associated with excessive inpatient stays when compared with national averages and that these excess days can be difficult to eliminate. The second demonstrated that this population was a major source of inpatient readmissions, accounting for about 90 percent of individual medical and surgical rehospitalizations [15].

Although this study focused on evaluation of adult medicine inpatients at the community level, it demonstrated the substantial impact of this service on hospital volumes, throughput, and outcomes. The importance of these impacts is magnified by the fact that the needs of these patients, including hospitalization, are not predictable and difficult to plan.

For providers and payers of health care, the needs of adult medicine patients will probably constitute an increasing challenge in the years ahead. Among providers, the difficulties of managing adult medicine patients reduce their attractiveness to primary care physicians, home health agencies, and nursing homes. As a result, the burden of their care is frequently left to acute hospitals and emergency departments. For payers, the amounts and unpredictability of care required by adult medicine patients can challenge financial resources available to Accountable Care Organizations, insurance plans, and other mechanisms [7] [9] [10].

These challenges suggest the need for further development and sharing of information concerning the needs and care of adult patients. More importantly, this need is justified by the fact that adult medicine patients include the most disadvantaged members of local communities through their clinical and functional disabilities. Such an approach can support the provision of effective care for these individuals and the delivery of services that they deserve.

\section{Conclusions}

Using the data concerning adult medicine utilization in the metropolitan area of Syracuse, New York, it is clear that this service includes the largest volumes of hospital inpatients in the community. This information, as well as the types of patients that use this service, suggests that adult medicine utilization is also a major factor in the use of inpatient hospitals elsewhere.

The data from the metropolitan area of Syracuse also suggest that the adult medicine population exerts major influences on hospital efficiency and outcomes. The examples from this study concerning inpatient lengths of stay and readmissions demonstrate the challenges in clinical management posed by this population for individual hospitals.

These points suggest that, as the need for improvements in hospital efficiency and outcomes increase, acute care facilities will need to improve their abilities to manage adult medicine inpatients. This will be a challenging process, yet also a beneficial one. It will improve the functioning of hospitals at the community level, and more importantly, the health of major populations whom they serve.

\section{References}

[1] Dentzler, S. (2011) Urgent Measures for an Old Problem. Health Affairs, 30, 1626. http://dx.doi.org/10.1377/hlthaff.2011.0961

[2] Auerbach, D.L. and Kellerman, A.L. (2011) A Decade of Health Care Cost Growth Has Wiped Out Real Income Gains for an Average US Family. Health Affairs, 30, 1630-1636. http://dx.doi.org/10.1377/hlthaff.2011.0585

[3] Levey, N.N. (2012) The Election and the Nation's Fiscal Plight Aim the Spotlight Again on Medicare. Health Affairs, 31, 2163-2167. http://dx.doi.org/10.1377/hlthaff.2012.0949

[4] McKinney, M. (2012) No Consensus: Healthcare Systems Slam NQF over Support of Readmissions Measure. Modern Healthcare, 42, 6-7, 12.

[5] McKinney, M. (2012) Sneak Preview: Hospitals Grateful for Advance Look at How Value-Based Purchasing Will Work, But Grumble about Its Complexity. Modern Healthcare, 42, 6-7.

[6] Martin, A.B., Hartman, M., Whittle, L. and Catlin, A. (2014) National Health Spending in 2012: Rate of Health Spending Growth Remain Low for the Fourth Consecutive Year. Health Affairs, 33, 67-77. http://dx.doi.org/10.1377/hlthaff.2013.1254

[7] Evans, M. (2012) The Early Returns on Accountable Care. Modern Healthcare, 42, S1-S5.

[8] Ayanian, J.Z. and Van der Wees, P.J. (2012) Tackling Rising Health Care Costs in Massachusetts. New England Jour- 
nal of Medicine, 367, 790-793. http://dx.doi.org/10.1056/NEJMp1208710

[9] Evans, M. (2012) Bumpy Start: While Medicare's ACO program Is Growing Rapidly, Technology Snags Threaten Success. Modern Healthcare, 42, 6-7.

[10] Fisher, E.S., Shortell, S.M., Kriendler, S.A., Van Citters, A.D. and Larson, B.K. (2012) A Framework for Evaluating the Formation, Implementation, and Accountable Care Organizations. Health Affairs, 31, 2368-2378. http://dx.doi.org/10.1377/hlthaff.2012.0544

[11] Larson, B.K., Van Citters, A.D., Kriendler, S.A., Carluzzo, K.L., Gbernudu, J.N., Wu, F.M., Nelson, E.C., Shortell, S.M. and Fisher, E.S. (2012) Insights from Transformations under Way at Four Brookings-Dartmouth Accountable Care Organization Pilot Sites. Health Affairs, 31, 2395-2406. http://dx.doi.org/10.1377/hlthaff.2011.1219

[12] Hoonhout, L.H., deBruijne, M.C., Wagner, C., Zegers, M., Waaijman, R., Spreeuwenberg, P., Asscheman, H., van der Wal, G. and Tulder van, M.W. (2009) Direct Medical Costs of Adverse Events in Dutch Hospitals. BMC Health Services Research, 9, 27. http://dx.doi.org/10.1186/1472-6963-9-27

[13] Fuller, R.L., McCullough, E.C., Bao, M.Z. and Averill, R.F. (2009) Estimating the Costs of Potentially Preventable Hospital Complications. Health Care Financing Review, 30, 17-32.

[14] Lagoe, R.J. and Westert, G.P. (2010) Evaluation of Hospital Inpatient Complications: A Planning Approach. BMC Health Services Research, 10, 200. http://dx.doi.org/10.1186/1472-6963-10-200

[15] Lagoe, R.J., Nanno, D.S. and Luziani, M.E. (2012) Quantitative Tools for Addressing Hospital Readmissions. BMC Research Notes, 5, 620. http://dx.doi.org/10.1186/1756-0500-5-620

[16] Lagoe, R., Paskinski, T., Kronenberg, P., Quinn, T. and Schaengold, P. (2006) Linking Health Services at the Community Level. Healthcare Quarterly, 9, 60-65. http://dx.doi.org/10.12927/hcq..18229 